\title{
Study on Failure Plane of Bulk Solid in Squat Silos
}

\author{
Changbing Chen*
}

Department of Civil Engineering, Hefei University, Hefei 230022, China

\begin{abstract}
With the increasing volume demand of silos, squat silo diameters are bigger and bigger. However, present wall pressure computation methods are mostly based on small diameter silos. To solve this problem, systematical research on the wall pressure in squat silos is of great importance. For now, in the Chinese code the wall pressure computation methods are based on the limit equilibrium theory to be calculated, which define the orientation of the failure plane in the bulk solid within the silo. The rupture angle is a key parameter to silos' wall pressure. Therefore the value and direction of rupture angle are researched by theoretical method in this paper, which has heavy significance and provide an important basis for the large diameter silo design.
\end{abstract}

Keywords: Failure Plane, Bulk Solid, Squat Silo, Wall Pressure

\section{INTRODUCTION}

Silos are structures that have always concerned mankind due to their capacity to store bulk solid, such as grain, coal, cement and so on. With the increasing production demand, the demand of silo volume increases continuously. Diameters of squat silos are bigger and bigger. The maximum diameter of present silos exceeds 100 meters [1].

With the passing of time, knowledge about silos has been further developed. However, this knowledge is mostly based on small silos whose diameter is smaller than 20 meters. There is little system research on large diameter silos whose diameter is larger than 20 meters. Scale effect is considered to particularly important to silos [2]. Therefore, it is meaningful to study on larger diameter silos.

Many scholars studied on silo pressure with theoretical analysis, such as Janssen (1895), Airy (1897), Reimbert M and Reimbert A [3], Walker, Walkers, Coulomb, Rankine, Jenike, Liu, Yuan etc [1-8]. Most of this research applied to small diameter silo. Only little system research directed to large diameter silos. Yuan (2004) studied static wall pressure on large diameter silos used limit equilibrium method in her $\mathrm{PhD}$ thesis. Part of her research was adopted in China Code for design of reinforced concrete silos (GB50077-2003) [9].

Wall pressure is a key parameter to silos' design. It has an important effect on the safety and efficiency of silos. At present, the wall pressure calculation method in the Chinese code are based on the limit equilibrium theory, which define the orientation of the failure plane in the bulk solid within the silo.

In this paper, the angles of failure plane in the bulk solid within squat silos are discussed.

*Address correspondence to this author at the Department of Civil Engineering, Hefei University, Hefei 230022, China;

Tel: +86-551-2158458; Fax: +86-551-2158467;

E-mails: ccbahhf@163.com,czb1108@hfuu.edu.cn

\section{THE RUPTURE ANGLE IN CHINA'S CODE}

In China's code [9], the Rankine active earth pressure formula is adopted in the calculation of wall pressure in squat silos. But when the top of the stored bulk materials is a conical pile, the Rankine formula does not work, because the Rankine theory must be based on the assumptions that the interface between the retaining wall and the soil is erect and smooth, and that the top plane of the bulk materials behind the retaining wall is horizontal. Consequently, the Appendix C in China's Code (GB50077-2003) [9] indicate the effect of conical pile must be taken into account to calculate the wall pressure of large diameter silos $\left(d_{\mathrm{n}} \geq 24 \mathrm{~m}\right)$ with the following formula by different rupture angle.

A circular silo with stored-bulk-solid is taken into consideration and shown in Fig. (1). The top of the bulk solid in Fig. (1) has a conical shape, and the angle of the top cone is denoted by $\beta$, which is always regarded as the surcharge angle of the bulk solid. The central line of the silo is $\mathrm{O}_{1} \mathrm{O}_{2}$. The line $\mathrm{AC}$ is the failure plane with an angle $\theta$ to the vertical. The planes from the rupture point $\mathrm{A}$ to the cone tip $\mathrm{O}_{1}$ in Fig. (2) have angle $\theta_{0}$, which can be calculated by

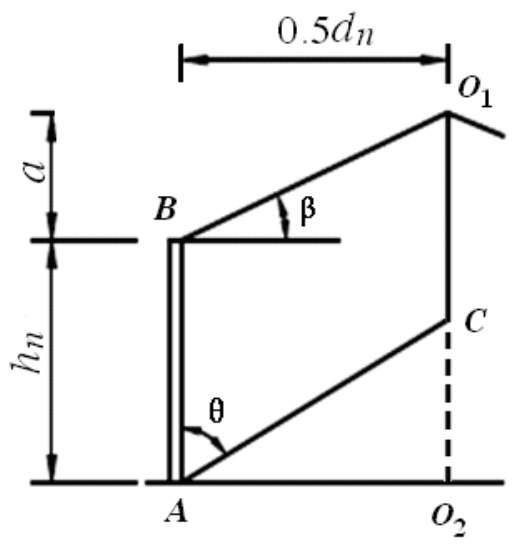

Fig. (1). The failure plane cuts the central line of the silo. 


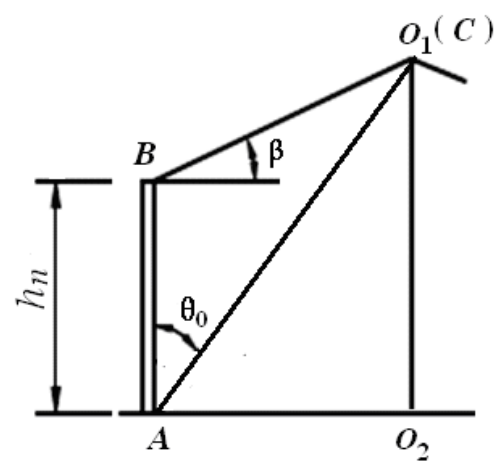

Fig. (2). Angles of failure plane $\theta=\theta_{0}$.

$\cot \theta_{0}=2 \delta+\tan \beta$

$\delta=h_{n} / d_{n}$

According to the Appendix $\mathrm{C}$ in China's Code, when the rupture angle $\theta$ is greater than $\theta_{0}$ which is shown in Fig. (2), in this case the pressure can be computed by Eq. 3-5.

$\cot \theta=-\cot \varphi+\frac{\sqrt{2[1+\cos 2 \varphi+\sin 2 \varphi(\tan \beta+6 \delta)]}}{\sin 2 \varphi}$

$\lambda_{k 1}=\frac{1}{12 \delta^{2}}(6 \delta+\tan \beta-\cot \theta) \cot (\theta+\varphi)$

$p_{h}=\lambda_{k 1} \gamma h_{n}$

where $\varphi$ is the internal friction angle, $\lambda_{k l}$ is the lateral pressure coefficient, $p_{h}$ is the lateral pressure, and $\gamma$ is the density of the bulk materials.

In another case the rupture angle $\theta$ is less than or equal to $\theta_{0}$ which is shown in Fig. (3), the pressure can be computed by Eq. 6-10.

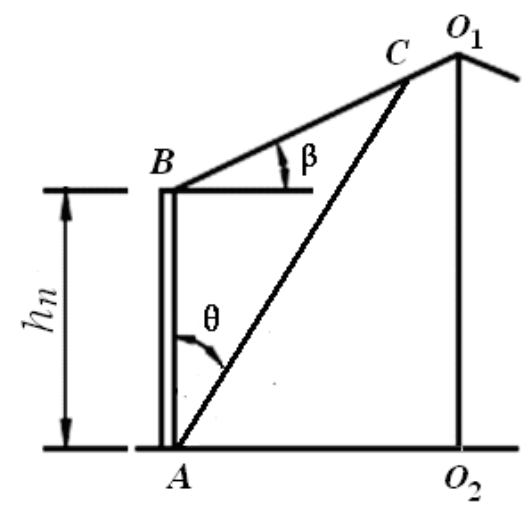

Fig. (3). Angles of failure plane $\theta<\theta_{0}$.

$$
\begin{aligned}
& \tan (\theta+\beta)=-\tan \psi+\sqrt{(\tan \psi+\cot \psi)(\tan \psi+\tan \beta)} \\
& \psi=\varphi-\beta(\varphi \neq \beta) \\
& \lambda_{k 2}=\frac{\cos ^{2} \varphi}{\left[1+\sqrt{\frac{\sin (\varphi-\beta) \sin \varphi}{\cos \beta}}\right]}
\end{aligned}
$$

$$
\begin{aligned}
& \eta=1-\frac{1}{3}(2 \delta+\tan \beta) \tan \theta \\
& p_{h}=\gamma h_{n} \lambda_{k 2} \eta
\end{aligned}
$$

where $\lambda_{\mathrm{k} 2}$ is the lateral pressure coefficient and $\eta$ is the correction factor.

\section{ANALYSIS OF THE ORIENTATION ON FAILURE PLANE}

\subsection{First Case}

According to the Appendix B in China's Code [9], the internal friction angle of bulk solid is range between $22^{\circ}$ and $40^{\circ}$. Following the parameters $\theta_{0}$ and $\theta$ calculated by Eq. 1 and Eq. 3, respectively, which present whether the first case shown by Fig. (1) is reasonable.

From Fig. (4-9), we can see that when $0 \leq \delta \leq 1, \theta<\theta_{0}$. And further, the parameter $\theta$ is calculated on the basis of different internal friction angle and aspect ratio $\delta$, which is always less

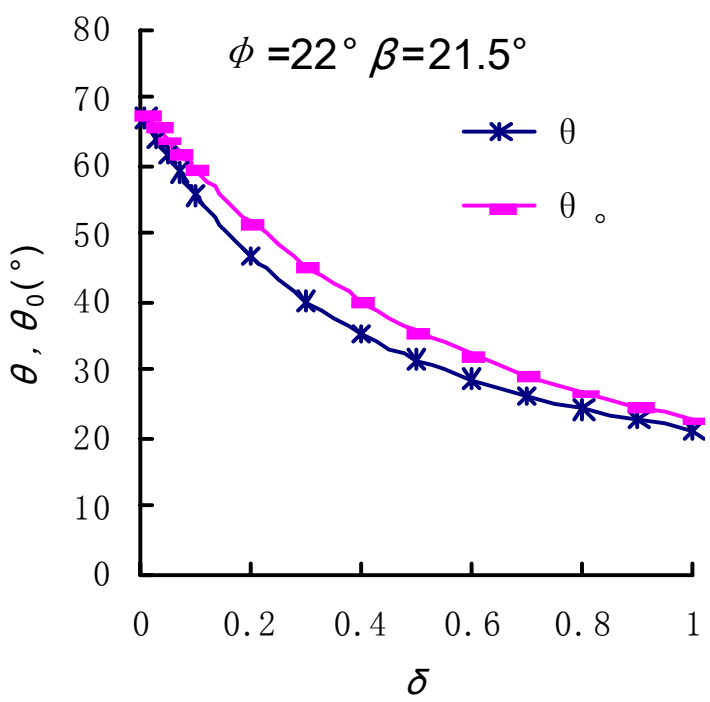

Fig. (4). Rupture angle calculated by Eq. 3 with $\varphi=22^{\circ}$.

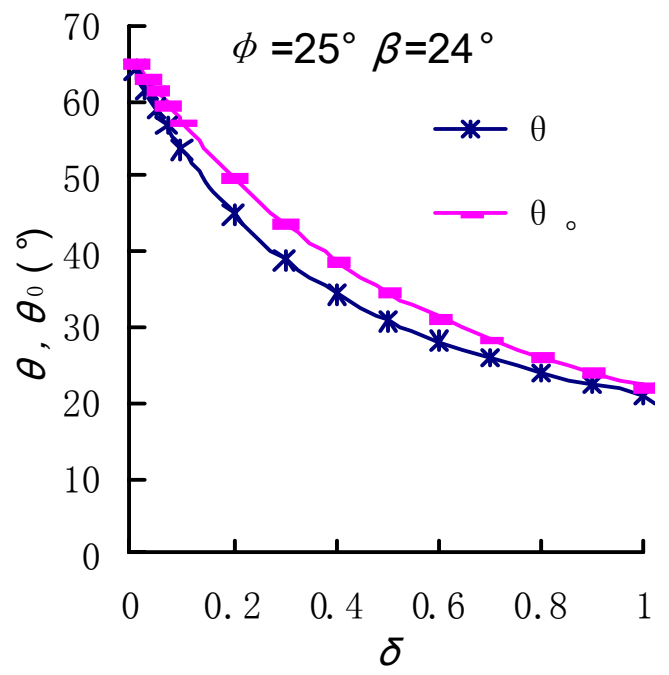

Fig. (5). Rupture angle calculated by Eq. 3 with $\varphi=25^{\circ}$. 


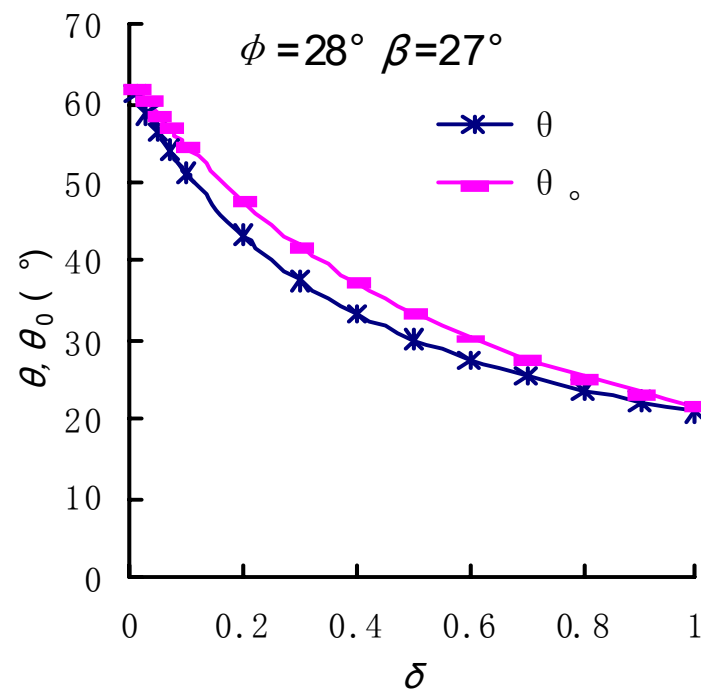

Fig. (6). Rupture angle calculated by Eq. 3 with $\varphi=28^{\circ}$.

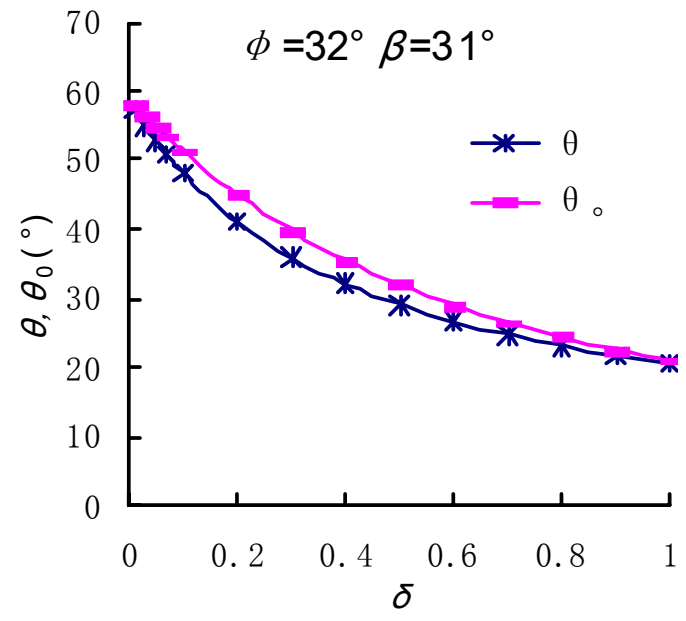

Fig. (7). Rupture angle calculated by Eq. 3 with $\varphi=32^{\circ}$.

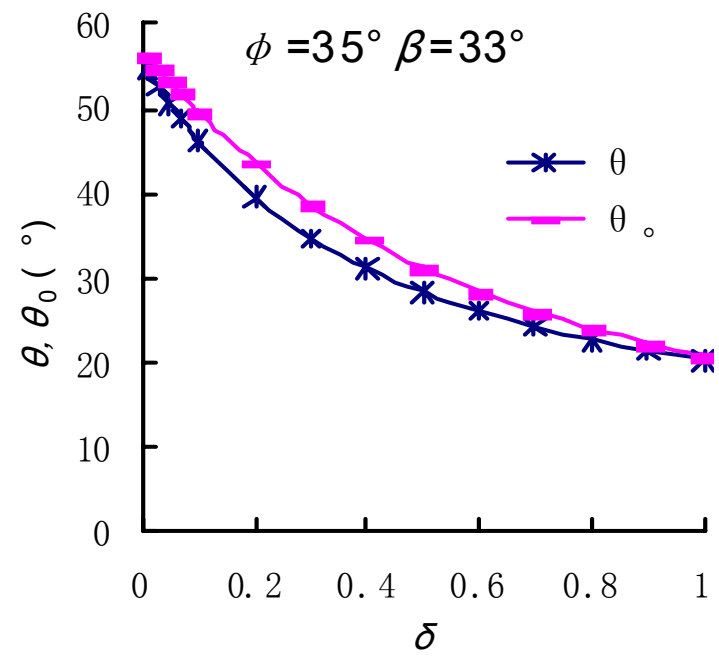

Fig. (8). Rupture angle calculated by Eq. 3 with $\varphi=35^{\circ}$.

than the parameter $\theta_{0}$. Thus, in the proposed method, the parameter $\theta$ calculated by Eq. 3 apparently contradict the hypothesis that the failure plane cuts the central line of the silo.

\subsection{Second Case}

In another case the rupture angle $\theta$ is less than or equal to $\theta_{0}$ which is shown in Fig. (3) and calculated by Eq. 6.

Fig. (10-15) shows that the parameter $\theta$ is greater than $\theta_{0}$ for the most part. And further, the parameter $\theta$ is calculated

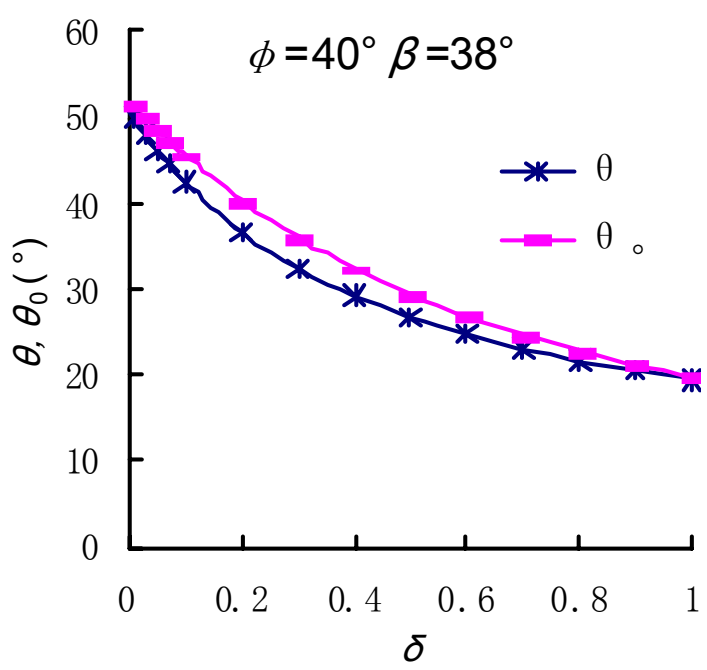

Fig. (9). Rupture angle calculated by Eq. 3 with $\varphi=40^{\circ}$.

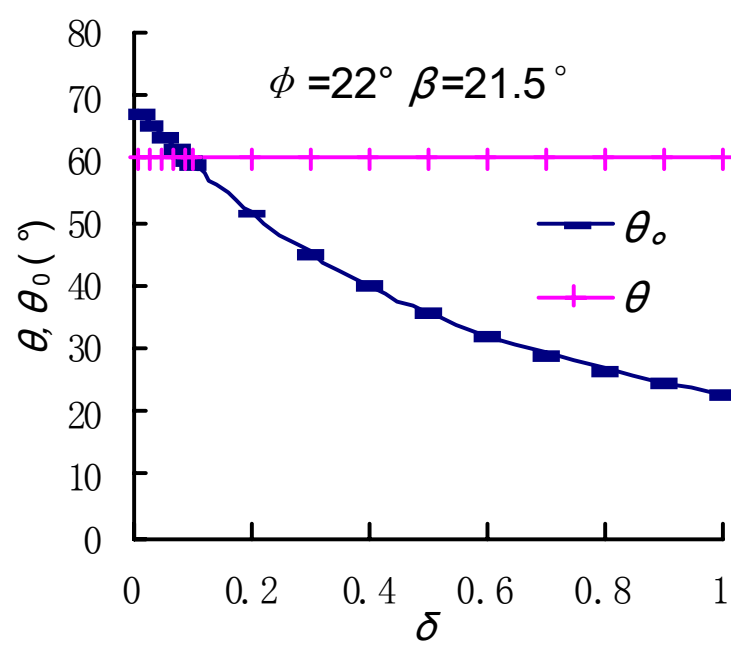

Fig. (10). Rupture angle calculated by Eq. 6 with $\varphi=22^{\circ}$.

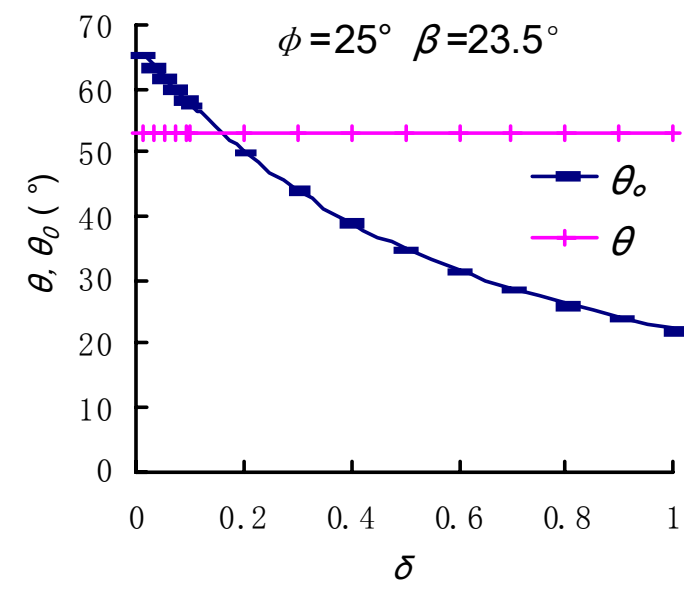

Fig. (11). Rupture angle calculated by Eq. 6 with $\varphi=25^{\circ}$. 


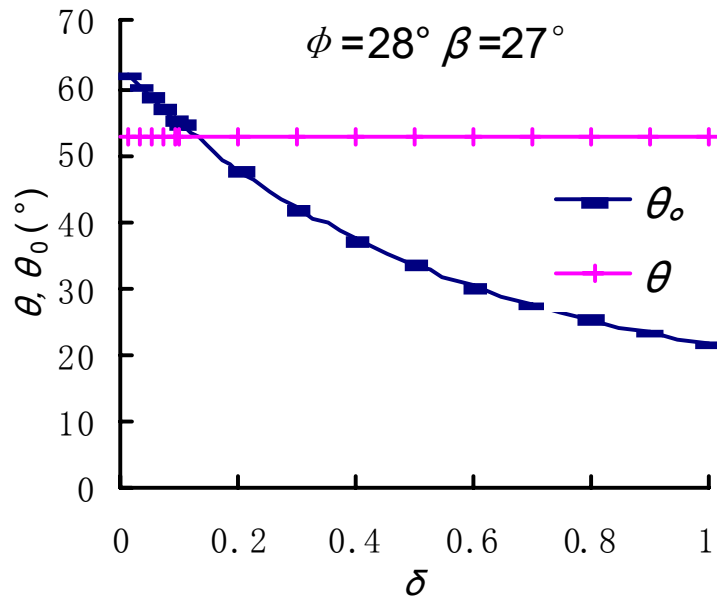

Fig. (12). Rupture angle calculated by Eq. 6 with $\varphi=28^{\circ}$.

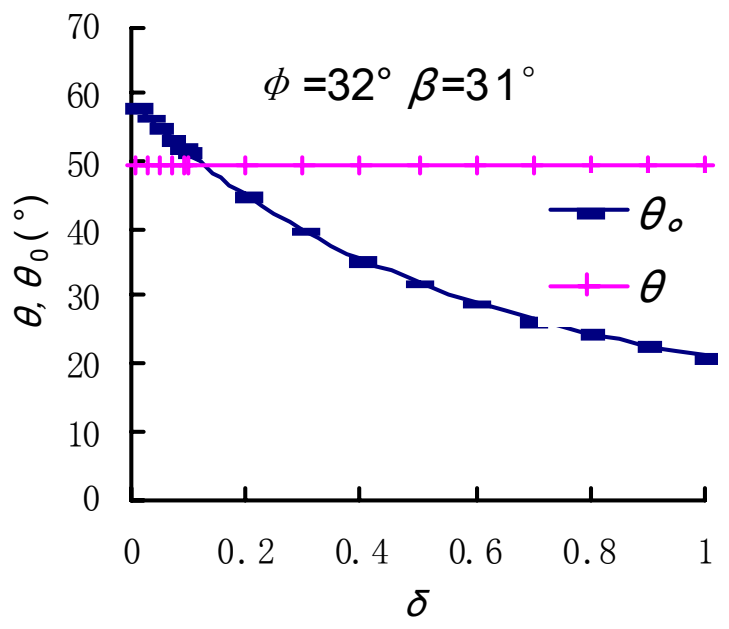

Fig. (13). Rupture angle calculated by Eq. 6 with $\varphi=32^{\circ}$.

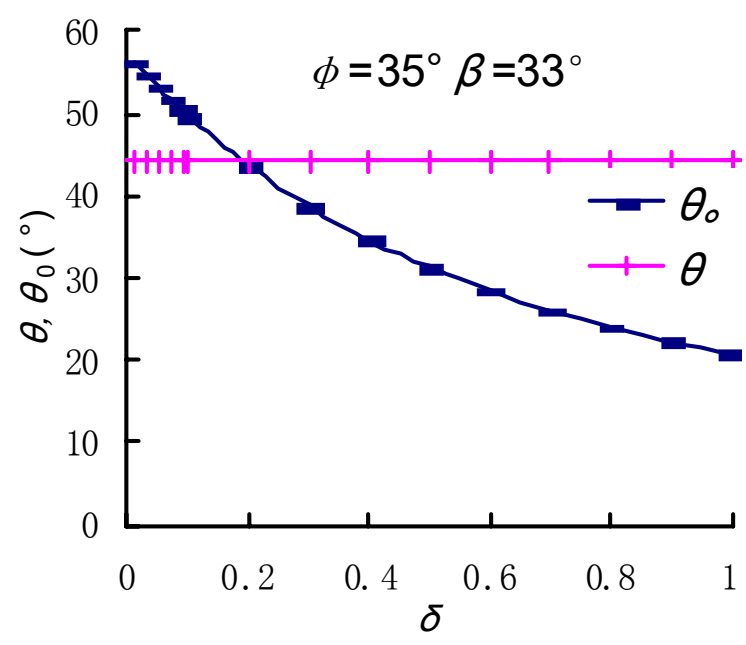

Fig. (14). Rupture angle calculated by Eq. 6 with $\varphi=35^{\circ}$.

on the basis of different internal friction angle and aspect ratio $\delta$, which is mostly greater than the parameter $\theta_{0}$. In practice, the aspect ratio of squat silos is about 0.2 to 1.0.Thus, in the second case, the parameter $\theta$ calculated by Eq. 6 obviously disagree with the assumption that the rupture plane reaches the top surface of the storage.

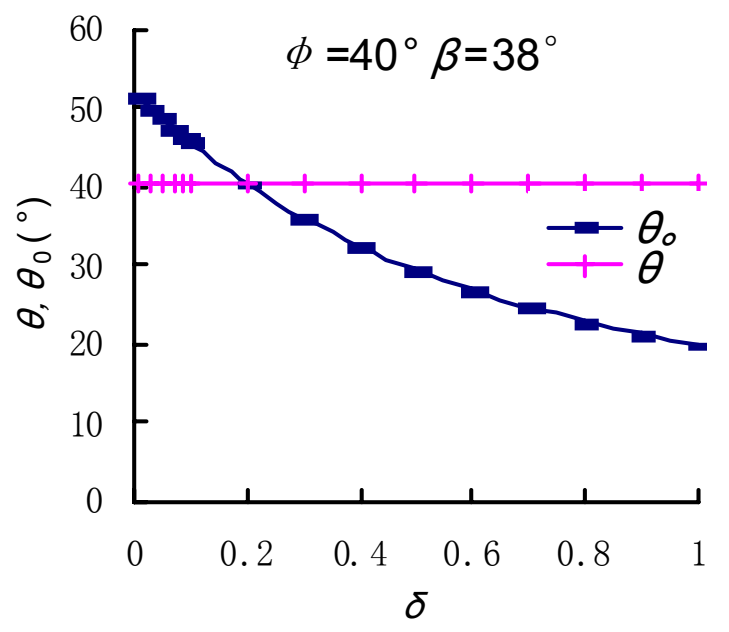

Fig. (15). Rupture angle calculated by Eq. 6 with $\varphi=40^{\circ}$.

\subsection{Analysis and Synthesis}

The rupture angles calculated by Eq. 3 and Eq. 6 appear to contradict assumptions those the orientations were shown in Figs. (1 and 3). In the second case the rupture angle $\theta$ is mostly greater than or equal to $\theta_{0}$, then let $\theta$ equal to $\theta_{0}$, we obtain .When correction factor is constant, Eq. 10 just a reducible Coulomb formula [1]. By more calculation even $\theta$ less than $\theta_{0}$, we also get. To compute wall pressure of large diameter squat silos, the reducible Coulomb formula is suitable according to the research results of Yuan [1]. If Eq. 10 is select to calculate the wall pressure, we must make it clear that the parameter $\theta$ is not always less than $\theta_{0}$.

\section{CONCLUSIONS}

Through theoretical and empirical analysis, this thesis reached the following conclusions.

In general, the failure plane of stored-bulk-solid can not cut the central line of silo. Thus, the Eq. 5 disagrees with the wall pressure in the squat silos.

Only when the aspect ratio $\delta$ is very small numbers to nearly 0 , the failure plane can meet the top of the stored bulk materials.

To compute wall pressure of squat silos, the reducible Coulomb formula is reasonable. But the parameter $\theta$ is often greater than $\theta_{0}$.

\section{CONFLICT OF INTEREST}

Declared none.

\section{ACKNOWLEDGEMENTS}

This research was supported by The Anhui Provincial Key Science Research Project in Colleges and Universities (N0. KJ2010A294).

\section{REFERENCES}

[1] Y. Fang, "Analysis of bulk-solid pressures on curve walls and its engineering application", $\mathrm{PhD}$ thesis, Dalian University of Technology, China, 2004. (in Chinese)

[2] A. M. Sanad, J.Y. Ooi, F.G. Holst, and Rotter, J.M., "Computations of granular flow and pressures in a flat-bottomed silo", J. Eng. Mech., vol. 127, pp. 1033-1043, 2001. 
[3] M. Reimbert, and A. Reimbert. Silos: Theory and Practice. Trans Tech Publications: Clausthal, 1976.

[4] C. Changbing, "Research on lateral bulk-solid pressures on silo's wall", $\mathrm{PhD}$ thesis, Hefei University of Technology, China, 2006. (in Chinese)

[5] L. Dinghua, and H. Jiping, "Research of lateral pressure upon wall of reinforced concrete silo", J. Building Struc., vol. 16, pp. 57-63, 1995. (in Chinese)

[6] L. Dinghua, and W. Yihua, "Calculation and testing of lateral pressure in a reinforced concrete. silo", Architech. Sci., vol. 14, pp. 14-18, 1998. (in Chinese)
[7] A .W. Jenike, "A theory of flow of particulate solids in converging and diverging channels based on a conical yield function" Powder Technol., vol. 50, pp. 229-236,1987.

[8] J. Y. Ooi, "Bulk solids behavior and silo wall pressure", $\mathrm{PhD}$ thesis, University of Sydney, 1990.

[9] C. Yuanrui, G. Hengshi, Y. Hailong, and P. Weimin. GB500772003 China code design of reinforced concrete silo. China Planning Press: Bejing (2004). (in Chinese)

(c) Changbing Chen; Licensee Bentham Open.

This is an open access article licensed under the terms of the Creative Commons Attribution Non-Commercial License (http://creativecommons.org/licenses/_by-nc/3.0/) which permits unrestricted, non-commercial use, distribution and reproduction in any medium, provided the work is properly cited. 